Article

\title{
Do Japanese Students Overestimate or Underestimate Their Knowledge of English Loanwords More than Non-loanwords on Yes-No Vocabulary Tests?
}

\author{
Raymond Stubbe \\ Kyushu Sangyo University \\ doi: http://dx.doi.org/10.7820/vli.v03.1.stubbe
}

\begin{abstract}
English loanwords (LWs), gairaigo in Japanese, make up a much greater percentage of the Japanese language than many university English teachers realize, especially if their native language is not Japanese. Unfortunately, a gairaigo bias exists which has made these LWs unpopular amongst teachers and researchers. The aim of this study is to compare student over-estimation and under-estimation of their knowledge of English LWs on yes-no vocabulary tests with an equal number of non-loanwords (NLWs). Undergraduate students from four Japanese universities $(n=455)$ took two vocabulary tests of their receptive and passive recall knowledge of LWs and NLWs. Six LWs and six NLWs from each of the eight JACET 8000 levels were tested in a selfreport yes-no test followed by a passive recall translation test (English to Japanese) of the same 96 items. Overall, over-estimation rates were nearly equal at $24.6 \%$ for LWs and $25.8 \%$ for NLWs. Additionally, overestimation was more prevalent for NLWs at the higher three frequency levels $(1 \mathrm{~K}-3 \mathrm{~K})$, nearly equal with $\mathrm{LWs}$ at the $4 \mathrm{~K}$ level and then more prevalent for the LWs at the lower four frequency levels $(5 \mathrm{~K}-8 \mathrm{~K})$, suggesting that student knowledge of NLWs is weak even at the higher frequency levels. Under-estimation, on the other hand, was much more prevalent for LWs $(4.4 \%$ versus $0.7 \%)$. Six of the 48 LWs actually had higher passive recall test scores than yes-no test scores. These results suggest that although students do not over-estimate their knowledge of LWs more than NLWs on yes-no vocabulary tests, they do underestimate their LW knowledge much more than NLWs.
\end{abstract}

Keywords: over-estimation of lexical knowledge; loanwords; yes-no vocabulary tests; passive recall knowledge; JACET 8000.

\section{Background}

\subsection{English LWs in Japanese}

The Japanese language contains thousands of English loanwords (LWs), "many of which are well-established and in universal use" (Kay, 1995). It has been estimated that about half of the most common 3,000 words of English have some borrowed form in Japanese (Daulton, 1998). Of a random selection of words 
contained in the reading sections (parts four and five) of two official TOEIC Bridge Practice Tests (Ashmore et al., 2007), 53\% were English LWs in Japanese (Stubbe, 2010). In that study, LW recognition was found to be significantly better than NLW recognition, especially among lower-level students.

A distinction between LWs which appear in Japanese and the term cognates will be made for this study. Whereas LWs are words borrowed into an L1 from another language (Daulton, 2008), cognates can be considered as lexical items shared between two languages, often occurring when "there is a strong lexical resemblance between the target language and the learner's mother tongue" (Eyckmans, 2004, p. 24). Naturally, no such resemblance exists between Japanese and English.

Although LWs appear to make up a sizable portion of students' English vocabulary, some of their university teachers may be unaware of this. A focus group consisting of 18 university English teachers (14 native English speakers and 4 Japanese teachers), most of whom had been teaching the same vocabulary lists to students for at least two years, considered English LWs in Japanese. The members were asked what percentage of the first year word list they thought were LWs. Responses ranged from $17 \%$ through $35 \%$, plus one outlier of $60 \%$ (from a vocabulary testing researcher). The actual LW rate of $53 \%$ was far above the focus group's mean estimate of 29\% (including the outlier), suggesting that many of these English teachers were not aware of the prevalence of English LWs in Japanese.

There also appears to be a prevalent bias against LWs, known as gairaigo in Japanese meaning "words from abroad." Daulton (2011) refers to this as a "gairaigo bias." Uchida (2007) and Daulton (2011) both explain that university students overwhelmingly reported that their junior or senior high-school English teachers either avoided references to gairaigo in the classroom or that if they did refer to it, it was spoken of negatively. In addition to secondary school teachers, some university English teachers from abroad also seem to suffer from this gairaigo bias. Shepherd (1996) suggested that gairaigo should be avoided in the classroom. Simon-Maeda (1995) states that LWs having meanings in Japanese which differ from those in English, "provides the most headaches for EFL teachers." More recently, Masson (2013) reported that her students overestimated their knowledge of word meaning for three LWs $(10 \%$ of the LWs tested). These three LWs were labeled as "distant false friends" (see Uchida, 2001), which are LWs having L1 meanings differing from L2. According to Masson (2013, p. 10), these LWs "are particularly problematic for students who are lulled into a false sense of familiarity, but do not notice that the meaning has changed." Overestimation was not the only problem with LWs identified in that study, a second was usage. On five other LWs, all having meanings matching or close to their L2 equivalents, the students made collocational or word-placement errors. Five of $30(17 \%)$ does not appear to be overly excessive. Unfortunately, NLWs were not included in that study to provide a base for comparison of the meaning and usage errors. This omission coupled with the fact that only $27 \%$ of the LWs ( 8 of 30 ) formed the basis for the entire article may suggest that Masson also suffers from gairaigo bias.

One study that did investigate differences in student knowledge of LWs versus NLWs is the pilot to the present study (Stubbe \& Yokomitsu, 2012). In that study, 
students $(n=71)$ were given two vocabulary tests: a yes-no (passive recognition) test of $60 \mathrm{LWs}$ and 60 NLWs from all eight levels of the JACET List of 8000 Basic Words (2003) (hereinafter J8000); followed by a passive recall (L1 to L2 translation) test of the same 120 words. This pilot study found that on the yes-no test Japanese university students' $(n=71)$ LW knowledge was almost $70 \%$ greater than their knowledge of NLWs (LW $M=77.5 \%$, standard deviation [SD] $=30.5 \%$; NLW $M=45.9 \%, \mathrm{SD}=36.2 \%)$. That investigation also found that passive recall knowledge as measured by an English to Japanese (L2 to L1) translation test of the same LWs was on average three times greater than their passive recall knowledge of the same NLWs (LW $M=40.0 \%$, SD $=37.1 \%$; NLW $M=13.1 \%$, SD $=25.4 \%$ ). These greater yes-no scores suggest that the participants were simply overestimating their lexical knowledge, especially on the NLWs. A review of the literature suggests different explanations for the gaps between yes-no test results and passive recall test scores.

\subsection{Gap between Yes-No Test and Passive Recall Tests Results}

The decrease in scores between the yes-no test and the passive recall test reported in the pilot study has been represented in the literature as students simply overestimating their lexical knowledge on the yes-no test (discussed below). In a study using a similar protocol to the pilot, Waring and Takaki (2003) reported a nearly $70 \%$ decrease in mean scores between a similar recognition checklist test $(61.2 \%)$ and an L2 to L1 passive recall translation test (18.4\%; same 25 items). In that study, 25 words in a graded reader were replaced with non-real words (for example, "sun" became "blund"), and students' ability to passively recognize and recall those 25 non-words was tested. It is possible that students who took the Stubbe and Yokomitsu yes-no test and the Waring and Takaki recognition checklist test were checking words which they thought they recognized and believed they knew a meaning of, but both studies' passive recall results showed that translations were often lacking or faulty. In other words, there appears to be a considerable gap between thinking one knows a word and actually being able to produce a correct translation for that word. In the pilot study, only $45.6 \%$ of the 120 items were attempted on the passive recall test, with $45.3 \%$ of these being incorrect (Stubbe \& Yokomitsu, 2012). In their study, Waring and Takaki (2003) also conducted a third, multiple choice, test of the same 25 non-words and reported a mean of 42.4\%. Discussing Waring and Takaki (2003), Nation and Webb (2011, p. 282) wrote:

Thus only a small number of words were learned well (per the results of the translation test), but quite a large number were learned at least partially. If only the translation test had been given, the amount of vocabulary learning from the reading would have been greatly underestimated.

It is possible that the students involved in the pilot study were checking yes-no items which they had partial knowledge of, and this could account for a portion of the gap between those yes-no and passive recall test scores. 
Milton (2009) offers another possible explanation for this recognitiontranslation gap. Words encountered repeatedly can become easy to recognize through implicit (incidental) learning. "Learning the meaning of new words, however, would require conscious processing at the semantic and conceptual levels (explicit learning)"' (Milton, 2009, p. 219). Accordingly, recognizing items on a yesno test should be much easier than providing correct L1 translations of those same items. Similarly, LWs, which are encountered in the L1 and thus can be learned implicitly, would be expected to have higher test scores than NLWs which are only encountered in the L2, and thus required explicit learning.

The "strength of vocabulary knowledge" hypothesis discussed in Laufer and Goldstein (2004) offers still another plausible explanation for the disparity between yes-no and translation test results. That study considered four types of vocabulary knowledge: active recall, where students can provide (recall) an L2 word following a prompt of the word in the L1; passive recall, where students can provide an L1 translation following an L2 prompt; active recognition, where students can select the correct L2 word out of a set of L2 distractors based on an L1 prompt; and passive recognition, where students can select the correct L1 translation out of a set of L1 distractors based on an L2 prompt. Laufer and Goldstein (2004) demonstrated that the order presented above (active recall through passive recognition) represented a hierarchy of learning difficulty in descending (hardest to easiest) order. Considering the recall versus recognition dichotomy, Laufer and Goldstein (2004, p. 408) explained that "recalling a word's meaning or form can be considered a more advanced degree of knowledge than recognizing it." Thus, scores on a passive yes-no recognition test would be expected to be higher than scores on an L2 to L1 translation (passive recall) test of the same words.

\subsection{Over-estimation and Under-estimation of Lexical Knowledge on Yes-No Tests}

Yes-no checklist vocabulary tests rely on students self-reporting their lexical knowledge. Unfortunately, self-reporting often results in over-estimation of lexical knowledge by test-takers claiming words they do not really know. Pseudowords were introduced to the yes-no test format by Anderson and Freebody (1983) as a means of checking for evidence of such over-estimation. Pseudowords were introduced to the field of second language acquisition by Meara and Buxton (1987). In such tests, knowledge of a real word is known as a "hit," while claiming knowledge of a pseudoword is a "false alarm." Not claiming knowledge of a real word is labeled a "miss" and not claiming knowledge of a pseudoword is a "correct rejection" (Anderson \& Freebody, 1983). In this paper, the terms hit and miss will be used frequently.

A number of other studies have reported yes-no test over-estimation as well as under-estimation. The degree of both varies widely from study to study depending, in part, on the type of test used to confirm actual lexical knowledge on the yes-no test, as well as the English proficiency levels of the participants. Mochida and Harrington (2003) report over-estimation and under-estimation rates of 5.4\% and

Vocabulary Learning and Instruction, 3 (1), 29-43. 
$6.4 \%$, respectively, for high-proficiency English learners, when yes-no test results were compared to a subsequently taken Vocabulary Levels Test (VLT; Nation, 1990; Schmidt, Schmidt \& Clapham, 2001). Stubbe, Stewart and Pritchard (2010) studying low-proficiency English learners reported rates of $14.5 \%$ and $33.1 \%$ respectively, when yes-no test results were compared to a multiple choice test of the same items. Stubbe (2012), also comparing yes-no test results with a multiple choice test of the same items, reported over- and under-estimation rates of $4.5 \%$ and $21.23 \%$, respectively. That study also reported significantly higher over-estimation rates for the lower-ability students. In a series of yes-no test experiments, Eyckmans (2004) reported yes-no test scores which were between $4.9 \%$ and $38.7 \%$ higher than subsequent L2 to L1 (Dutch to French) translation scores of the same items. Directly comparing each participant's score on each word tested in the yes-no tests with the same student/word score on the translation test in that study, Eyckmanns also reported over-estimation (yes-no hit matched with an incorrect translation) rates of between $30.6 \%$ and $48 \%$, with under-estimation (yes-no miss matched with a correct translation) rates ranging from $12.0 \%$ through $25.4 \%$. Perhaps surprisingly, overestimation rates were higher when cognates were excluded from the test results. Eyckmans found "that the cognates in the test were not responsible for the participants' tendency to overestimate their word knowledge" (2004, p. 85). It was also found that under-estimation rates were lower for non-cognate test items, leading Eyckmans to speculate that the students did not trust the cognates on the yes-no test likely because of a warning about the inclusion of pseudowords in the test instruction. However, upon seeing them again on the translation test they attempted translations.

\section{Aims}

This study aims to determine whether LW status significantly affects overestimation rates on a yes-no vocabulary test compared with a passive recall (L2 to L1) translation test of the same words.

\section{Method}

\subsection{Item Selection and Test Preparation}

For this study, an item pool was prepared consisting of 96 real-words (six LWs and six NLWs from each of the eight JACET 8000 (2003) levels) plus 32 pseudowords, for a total of 128 items. Included in this item pool were the nine best pseudowords as well as the top 40 real-words identified in Stubbe and Stewart (2012), plus four more NLWs from the pilot to this study (Stubbe \& Yokomitsu, 2012). The nine pseudowords were chosen by examining "the degree to which pseudowords have negative point-biserial correlations with total scores on the translation tests." The 40 real-words were selected "by examining phi (dichotomous) correlations between students' self-reports on given words and whether or not the same word was confirmed as known on the subsequent translation test" (Stubbe \& Stewart, 2012, p.5). The remaining 52 real-words were randomly selected as required from the eight levels of the JACET 8000 (2003). In selecting LWs and NLWs, part of speech was not taken into account. 
In selecting LWs no distinction was made concerning the type of LW encountered. Uchida (2001) discusses six types of Japanese-English cognates of varying degrees of difficulty, into which LWs can be classified (see Masson, 2013 for a concise overview). It was decided to ignore LW type, because determining LW type would be cumbersome for all 48 LWs; plus selecting some types of LWs while rejecting others would inevitably skew results in favor of either LWs or NLWs. All 48 randomly selected LWs were reviewed by a Japanese teacher of English to ensure that they all were in fact LWs. The same was done for the 48 randomly selected NLWs to make sure that none of them were LWs. Three LWs and five NLWs required replacement and these eight replacements were again checked by the same teacher to ensure they were of the proper LW status.

These 96 items (see Appendix) were used to create two vocabulary tests, the first being a passive recognition yes-no vocabulary test, which also included 32 pseudowords. These 128 real-words and pseudowords were all assigned random numbers (1-128) and ordered into the yes-no test accordingly. The second vocabulary test was a passive recall test of the same 96 items from English into Japanese. A passive recall test was chosen because translation ability is a strong indicator of which words students can actually understand while reading (Waring \& Takaki, 2003) and "asking participants to provide mother-tongue equivalents of the target language words was the most univocal way of verifying recognition" (Eyckmans, 2004, p. 77). The 96 items in this test were also assigned random numbers (1-96) for ordering. Participants were given the yes-no test at the beginning of one class in July or August 2012 and received the passive recall test toward the end of that same class. Tests were given in the same class in order to avoid any loss of yes-no - passive recall test pairings due to student absences in a subsequent class. The former test was a paper yes-no test in which the students signaled whether they knew a word or not by filling in either a yes bubble or a no bubble beside each item. Similar to Eyckmans (2004), test-takers were advised of the existence of pseudowords in the yes-no test instructions. Yes-no test forms were subsequently marked by running them through an optical scanner and the resulting data were converted into an Excel file for analysis.

The passive recall test forms, on the other hand, were hand-marked by three markers: one Japanese English instructor and two third-year students. Inter-rater reliability among these three markers was .92, and FACETS analysis (Linacre, 2012) revealed that the raters were basically equal with overall measures of $.02, .02$ and -.04 logits. One weakness of decontextualized passive recall tests deserves attention here. As many of the 96 words used in this study have multiple meanings, any one of those was considered correct, including katakana transcriptions of the LWs as long as the usage in Japanese also exists in English. Naturally, this would make LWs far easier to translate, but also easier to learn, at least on the single meaning level. Finally, informed consent was obtained from all participants.

\subsection{Participants}

Undergraduate students from 23 classes in four Japanese universities $(n=455)$ covering a wide range of English proficiency levels participated in this study.

Vocabulary Learning and Instruction, 3 (1), 29-43. 


\section{Results and Discussion}

Similar to the pilot study, the yes-no test mean was nearly double that of the passive recall test $(50.9 \%$ versus $28.2 \%$ of the 96 words). SDs were $17.9 \%$ and $12.7 \%$, respectively. Test reliabilities (Cronbach's alpha) were high at .96 and .92, respectively (see Table 1).

Table 1. Descriptive Statistics for YesNo and Passive Recall Tests $(n=455$, $k=96)$

\begin{tabular}{lccc}
\hline Test & Mean (\%) & SD (\%) & Reliability \\
\hline YN & 50.9 & 17.9 & .96 \\
PR & 28.2 & 12.7 & .92 \\
\hline
\end{tabular}

Note: YN and PR refer to yes-no and passive recall tests, respectively, for all Tables.

The second table breaks down yes-no and passive recall test results by LW status. On the yes-no test, LWs had $49.2 \%$ more reports than NLWs $(61.8 \%$ and $39.9 \%$, respectively). On the passive recall test, however, LWs had $166.7 \%$ more correct translations than NLWs (41.6\% and 14.9\%, respectively).

Table 2. Descriptive Statistics for Yes-No and Passive Recall Tests by Loanword Status $(n=455, k=48)$

\begin{tabular}{lcccc}
\hline Test & Mean (\%) & SD (\%) & Range (\%) & Low-High (\%) \\
\hline YN LWs & 61.8 & 9.8 & 89.6 & $6.25-95.8$ \\
YN NLWs & 39.9 & 9.0 & 85.4 & $0-85.4$ \\
PR LWs & 41.6 & 8.1 & 75.0 & $6.25-81.3$ \\
PR NLWs & 14.9 & 5.4 & 54.2 & $0-54.2$ \\
\hline
\end{tabular}

For purposes of comparison, Table 3 presents the LW means on both tests as well as the NLW means in separate columns. The difference in means was smaller for the LWs (20.2\% versus $25.0 \%$ for NLWs). The yes-no LW mean was 0.49 times greater than on the passive recall test, while the yes-no NLW mean was 1.73 times that of the passive recall test. It appears as if these participants did not over-estimate their LW knowledge more than their NLW knowledge.

Table 3. LWs versus NLWs Means by Both Tests (YN and PR)

\begin{tabular}{lcc}
\hline Test & LW mean (\%) & NLW mean (\%) \\
\hline YN & 61.8 & 39.9 \\
PR & 41.6 & 14.9 \\
Diff: YN-PR & 20.2 & 25.0 \\
\hline
\end{tabular}


Table 4 displays the LW and NLW means for the yes-no and passive recall tests in each of the eight J8000 levels. With the exception of the $3 \mathrm{~K}$ level on the yesno test, LW scores exceeded those of NLWs. LW scores at the $7 \mathrm{~K}$ and $8 \mathrm{~K}$ levels were higher than NLW scores at the $2 \mathrm{~K}$ and $3 \mathrm{~K}$ levels $(24.5 \%$ and $38.3 \%$ versus $34.5 \%$ and $19.3 \%$ ). It can also be seen that decreases between yes-no scores and passive recall scores were much greater for the NLWs at the $1 \mathrm{~K}$ through $4 \mathrm{~K}$ levels. As these higher frequency words are far more critical for students to master (Milton, 2009), NLW over-estimation is arguably a far more serious problem than that of LWs. However, if any under-estimation of knowledge also existed in the data, as with the cognates in Eyckmans (2004), over-estimation rates would be artificially reduced. To calculate accurate over-estimation and under-estimation rates, direct comparison of the two test forms was required (see Table 5).

Table 4. LW and NLW Means for Yes-No and Passive Recall Tests by J8000 Level $(k=6)$

\begin{tabular}{lcccc}
\hline J8000 level & YN LW (\%) & PR LW (\%) & YN NLW (\%) & PR NLW (\%) \\
\hline 1K & 88.2 & 75.0 & 82.5 & 40.5 \\
2K & 83.3 & 63.3 & 71.7 & 34.5 \\
3K & 51.8 & 28.5 & 54.2 & 19.3 \\
4K & 64.2 & 46.3 & 29.8 & 6.7 \\
5K & 48.8 & 31.7 & 17.8 & 2.5 \\
6K & 42.7 & 24.5 & 24.3 & 7.7 \\
$7 \mathrm{~K}$ & 49.0 & 24.5 & 18.0 & 2.2 \\
8K & 66.3 & 38.3 & 21.0 & 5.2 \\
Overall & 61.8 & 41.5 & 40.0 & 14.8 \\
\hline
\end{tabular}

Table 5. Direct Comparison of Yes-No Results and Passive Recall Test Scores, by Participant and Item (LW Result/NLW Result)

\begin{tabular}{|c|c|c|c|}
\hline & & \multicolumn{2}{|c|}{ Passive recall test } \\
\hline & & correct & incorrect \\
\hline \multirow{4}{*}{ Yes-No test } & hit & Confirmed correct & Over-estimation \\
\hline & & $37.2 \%$ / 14.2\% & $24.6 \%$ / $25.8 \%$ \\
\hline & miss & Under-estimation & Confirmed unknown \\
\hline & & $4.4 \% / 0.7 \%$ & $33.9 \%$ / $59.4 \%$ \\
\hline
\end{tabular}

\subsection{Direct Comparison of Yes-No Test and Passive Recall Test Results}

Similar to Stubbe (2012), Mochida and Harrington (2006) and Eyckmans (2004), this final analysis matched each student's response for each word on the yes-no test ( $n=455, k=48 \mathrm{LWs}$ and 48 NLWs) with his/her answer to that word 
on the passive recall test (answers left blank on the passive recall test were combined with incorrect responses for this analysis). Table 5 presents the results of this analysis, which resulted in four possible matches: (a) a yes-no hit matched with a passive recall test correct answer which was labeled "confirmed known"; (b) a yes-no hit matched with a passive recall test incorrect, labeled "over-estimation"; (c) a yes-no miss and a passive recall test correct was labeled "under-estimation"; and (d) yes-no miss and passive recall test incorrect was labeled "confirmed unknown." In this table, LW matches precede NLW matches, with the later also italicized. For example, $37.2 \% / 14.2 \%$ are the percentages of confirmed known matches for LWs and NLWs, respectively. As expected, confirmed known heavily favored the LWs, with the opposite for confirmed unknown. Together the confirmed known and confirmed unknown categories account for $71.08 \%$ and $73.58 \%$ of possible matches for LWs and NLWs, respectively. Perhaps not surprisingly, the NLWs were slightly more reliable. The remaining responses, over-estimation, and under-estimation are discussed below.

As mentioned, a hit matched with a non-correct translation (including blanks) was labeled over-estimation. Perhaps contrary to expectations, the LWs' percentage is slightly lower than the NLWs' $(24.6 \%$ versus $25.8 \%)$. It appears as if LW status (similar to cognate status) did not significantly effect over-estimation rates on the yes-no vocabulary test. If blanks are excluded from the analysis leaving actual translation attempts, the LWs had an error rate of $19.3 \%$ while the NLWs had a rate of $20.4 \%$.

It may be remembered that Eyckmans (2004) also found that underestimation occurred much more often with cognates than with non-cognates. In the final quadrant of Table 5, under-estimation, the LW results replicated this finding by exceeding the amount of the NLW' under-estimation by a considerable margin $(4.4 \%$ versus $0.7 \%)$. It may also be possible that the participants in this study did not trust some of the LWs on this yes-no test because of a warning about pseudowords in the test instructions, similar to Eyckmans (2004). To illustrate, the $4 \mathrm{~K}$ LW helicopter had the greatest amount of "under-estimation" at $21.8 \%$ of all students. Five other LWs also had higher passive recall test scores than yes-no test scores, while none of the NLWs did (see Appendix).

Table 6 breaks down the over-estimation quadrant in Table 5 by J8000 level. As mentioned above, only in this quadrant was the difference between LW and NLW results slight, suggesting that students may be able to recognize without being able to recall the meaning of LWs and NLWs in near equal measure. However, Table 6 suggests that over-estimation was more prevalent for NLWs at the higher three frequency levels, nearly equal with LWs at the $4 \mathrm{~K}$ level and then more prevalent for

Table 6. Over-estimation of LW and NLW Knowledge on the Yes-No Test Broken Down by J8000 Level $(n=455)$

\begin{tabular}{lcccccccc}
\hline \multicolumn{1}{c}{ J8000 level } \\
\hline Category & $1 \mathrm{~K}(\%)$ & $2 \mathrm{~K}(\%)$ & $3 \mathrm{~K}(\%)$ & $4 \mathrm{~K}(\%)$ & $5 \mathrm{~K}(\%)$ & $6 \mathrm{~K}(\%)$ & $7 \mathrm{~K}(\%)$ & $8 \mathrm{~K}(\%)$ \\
LWs & 14.6 & 23.6 & 28.2 & 26.4 & 22.5 & 21.9 & 27.0 & 32.4 \\
NLWs & 42.5 & 37.8 & 36.2 & 23.7 & 15.8 & 17.2 & 16.3 & 16.7 \\
\hline
\end{tabular}


the LWs at the lower four frequency levels. It appears that over-estimation or recognition without meaning recall was strongest for NLWs at the highest frequency level (ranging from $20.9 \%$ to $59.3 \%$ of students overestimating the $1 \mathrm{~K}$ NLWs, see Appendix), decreasing steadily through $5 \mathrm{~K}$, before basically leveling off. For the LWs, on the other hand, over-estimation started low at $1 \mathrm{~K}$, increased steadily through $3 \mathrm{~K}$, decreased from $4 \mathrm{~K}$ through $6 \mathrm{~K}$, before increasing to its highest value at $8 \mathrm{~K}$. Viewing lexical development as a process of moving from passive recognition to passive recall of meaning, we can see that for NLWs the gap between these two stages is greatest at the highest frequency level suggesting that these students still need to develop their passive recall of meaning ability for many of the most frequent English NLWs. As knowledge of NLWs decreased following word frequency level expectations, over-estimation decreased through $5 \mathrm{~K}$ for NLWs, then basically leveled off thereafter. For LWs, however, it appears as if the opposite occurred. With the highest frequency items, over-estimation was the least, while increasing (albeit unevenly) through to its highest level at $8 \mathrm{~K}$.

\section{Conclusion}

This study has investigated whether LW status significantly affects overestimation rates on a yes-no vocabulary test. Student recognition and translation abilities of 48 LWs and 48 NLWs, randomly selected from all levels of the JACET8000 list, were tested. Overall, it was found that the NLWs had slightly more over-estimation than the LWs. A breakdown of actual instances of over-estimation by J8000 frequency level revealed that, at the highest frequency levels, students over-estimated their knowledge of the NLWs considerably more than the LWs. As high frequency vocabulary is used much more often than low frequency, especially by L2 learners, it seems concerns regarding over-estimation might better be focused on NLWs. It was also found that lower frequency $7 \mathrm{~K}$ and $8 \mathrm{~K}$ LWs were better known than NLWs at the $2 \mathrm{~K}$ and $3 \mathrm{~K}$ levels. Additionally, students made more actual translation errors on the NLWs. The LWs, however, did attract considerably more under-estimation on the yes-no test.

This study does suffer from a number of limitations. The $92 \%$ inter-rater reliability amongst the three markers could be higher. Also, the selection of only six LWs and six NLWs from each J8000 could be considered too small to capture a truly representative sampling and thus allow for the skewing of the results. For instance, the LW jump at the $4 \mathrm{~K}$ level was possibly due to the influence of the single word helicopter. Sampling a greater number of words from fewer J8000 levels could help alleviate this weakness. Additionally, a limitation of single word (decontextualized) passive recall tests must be acknowledged. As many of the 96 words used in this study have multiple meanings, any one of those was considered correct, including katakana transcriptions of the LWs as long as the usage in Japanese also exists in English. Naturally, this would make LWs far easier to translate, but also easier to learn, at least on a single meaning level. Finally, it has been suggested in the literature that nouns are the easiest part of speech to learn (see Hirsh-Pasek \& Golinkoff, 2006 for a good discussion). As LWs are usually nouns, this could further contribute to their ease of learning. Not controlling the balance of parts of 
speech between the LWs and NLWs may have contributed to the dominance of LWs in these results.

Despite these weaknesses, these results may have implications for vocabulary testers and teachers. For testers of vocabulary, knowing which items are LWs while developing a test should help to better predict item performance. As LW scores at the $7 \mathrm{~K}$ and $8 \mathrm{~K}$ levels were higher than NLW scores at the $2 \mathrm{~K}$ and $3 \mathrm{~K}$ levels, not knowing which items in a test are LWs and building a test for Japanese students based only on word frequency levels could lead to some unexpected results. The lower level students could do relatively well compared to the high-level students based solely on their LW knowledge. It was found that although over-estimation rates are comparable to NLWs, students may also under-estimate their knowledge of some of the LWs when completing yes-no checklist tests.

For teachers, knowing the LWs in a list of vocabulary to be taught or used in a classroom could help them to better assist students in their lexical development. The LWs in the list sharing meanings and usages in both languages could be quickly reviewed before teaching the NLWs, which students tended to over-estimate their knowledge of at the highest frequency levels. Any LWs having meanings in Japanese which differ from English, called false friends (Uchida, 2001; recruit, for example) would require re-learning and this challenge could be anticipated and prepared for. Not preparing for such false friends could lead to frustrating misunderstandings between students and instructor, especially if the latter is a native English speaker unfamiliar with the pervasiveness of English LWs in Japanese. Instead of complaining about the headache of English LWs in Japanese, teachers (and researchers) should improve their LW knowledge so that they can better assist their students acquire the English vocabulary they require.

\section{Acknowledgements}

I thank Hoke Shintarou sensei, as well as the Kyushu Sangyo University Language Education and Research (LERC) staff for their assistance with marking the passive recall test. I would also like to thanks Messrs. Chris O'Sullivan, Dave Latz and Eric Miller, and their students for participating in this study. Finally, I also thank the many reviewers of this paper for their constructive comments.

\section{References}

Anderson, R. Cr., \& Freebody, P. (1983). Reading comprehension and the assessment and acquisition of word knowledge. In B. A. Hutson (Ed.), Advances in reading/language research (vol. 2; pp. 231-256). Greenwich, CT: JAI Press.

Ashmore, E., Carter, E., Duke, T., Hauck, M., Locke, M., \& Shearin, R. (2007). TOEIC® Bridge 公式ガイ ド\&問題集 (Official Guide and Exercise Books). Princeton, NJ: Educational Testing Service.

Daulton, F. E. (2011). On the origins of gairaigo bias: English learners' attitudes towards English-based loanwords in Japan. The Language Teacher, 35(6), 7-12.

Daulton, F. E. (2008). Japan's built-in lexicon of English-based loanwords. New York, NY: Multilingual Matters. 
Daulton, F. E. (1998). Loanword cognates and the acquisition of English vocabulary. The Language Teacher, 22(1), 17-25.

Eyckmans, J. (2004). Measuring receptive vocabulary size. Utrecht: LOT (Landelijke Onderzoekschool Taalwetenschap).

Hirsh-Pasek, K., \& Golinkoff, R. M. (Eds.). (2006). Action meets words: How children learn verbs. New York, NY: Oxford University Press.

JACET Basic Word Revision Committee. (2003). JACET list of 8000 basic words. Tokyo: Japan Association of Language Teachers.

Kay, G. (1995). English loanwords in Japanese. World Englishes, 14(1), 67-76. doi:10.1111/j.1467-971X.1995.tb00340.x

Laufer, B., \& Goldstein, Z. (2004). Testing vocabulary knowledge: Size, strength and computer adaptiveness. Language Learning, 54(3), 399-436. doi:10.1111/ j.0023-8333.2004.00260.x

Linacre, J. M. (2012). Facets computer program for many-facet Rasch measurement, version 3.70.0. Beaverton, OR: Winsteps.com. Retrieved from http://www. winsteps.com//index.htm

Masson, M.-E. (2013). How L1 loanwords can create a false sense of familiarity with L2 vocabulary meaning and usage. Vocabulary Learning and Instruction, 2(1), 8-14. doi:10.7820/vli.v02.1.masson

Meara, P., \& Buxton, B. (1987). An alternative to multiple choice vocabulary tests. Language Testing, 4(2), 142-154. doi:10.1177/026553228700400202

Milton, J. (2009). Measuring second language vocabulary acquisition. Bristol: Multilingual Matters.

Mochida, A., \& Harrington, M. (2006). Yes/No test as a measure of receptive vocabulary. Language Testing, 23, 73-98. doi:10.1191/ 02655322061 t321oa

Nation, I. S. P. (1990). Teaching and learning vocabulary. Boston, MA: Heinle and Heinle.

Nation, I. S. P., \& Webb, S. (2011). Researching and analyzing vocabulary. Boston, MA: Heinle.

Schmitt, N., Schmitt, D., \& Clapham, C. (2001). Developing and exploring the behaviour of two new versions of the Vocabulary Levels Test. Language Testing, 18, 55-89.

Shepherd, J. (1996). Loanwords: A pitfall for all students. The Internet TESL Journal, 2(2). Retrieved from: http://iteslj.org/Articles/Shepherd-Loanwords. html

Simon-Maeda, A. (1995). Language awareness: Use/misuse of loan-words in the English language in Japan. The Internet TESL Journal, 1(2). Retrieved from: http://iteslj.org/Articles/Maeda-Loanwords.html

Stubbe, R. (2012). Do pseudoword false alarm rates and overestimation rates in yes/no vocabulary tests change with Japanese university students' English ability levels? Language Testing, 29(4), 471-488. doi:10.1177/0265532211433033 
Stubbe, R., \& Stewart, J. (2012). Optimizing scoring formulas for yes/no vocabulary checklists using linear models. Shiken Research Bulletin, 16(2), 27. Retrieved from http://teval.jalt.org/node/12

Stubbe, R., \& Yokomitsu, H. (2012). English loanwords in Japanese and the JACET 8000. Vocabulary Education and Research Bulletin, 1, 10-11. Retrieved from http://jaltvocab.weebly.com/publications.html

Stubbe, R. (2010). Exploring the lexical challenge of the TOEIC $\mathbb{R}$ Bridge. In A. M. Stoke (Ed.), JALT 2009 conference proceedings (pp. 710-721). Tokyo: JALT. Retrieved from http://jalt-publications.org/proceedings/articles/84-jalt2009proceedings-contents

Stubbe, R., Stewart, J., \& Pritchard, T. (2010). Examining the effects of pseudowords in yes/no vocabulary tests for low level learners. Kyushu Sangyo University Language Education and Research Center Journal, 5, 5-23.

Uchida, E. (2007). Oral and written identification of L2 loanword cognates by Japanese learners of English. The Language Teacher, 31(9), 19-22.

Uchida, E. (2001). The use of cognate inferencing strategies by Japanese learners of English (Unpublished doctoral dissertation). Essex University, Colchester, UK.

Waring, R., \& Takaki, M. (2003). At what rate do learners learn and retain new vocabulary from reading a graded reader? Reading in a Foreign Language, 15, $130-163$. 


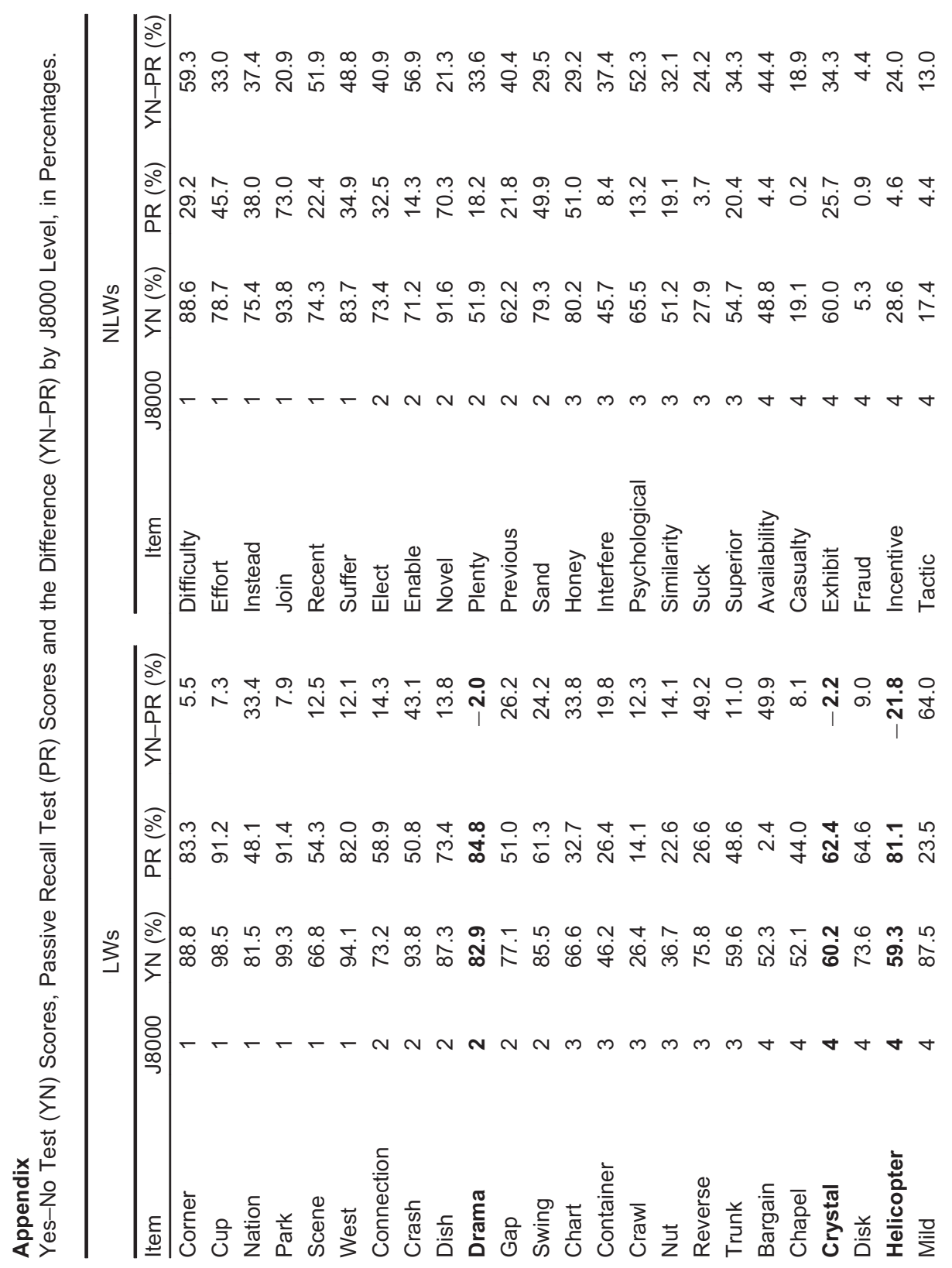




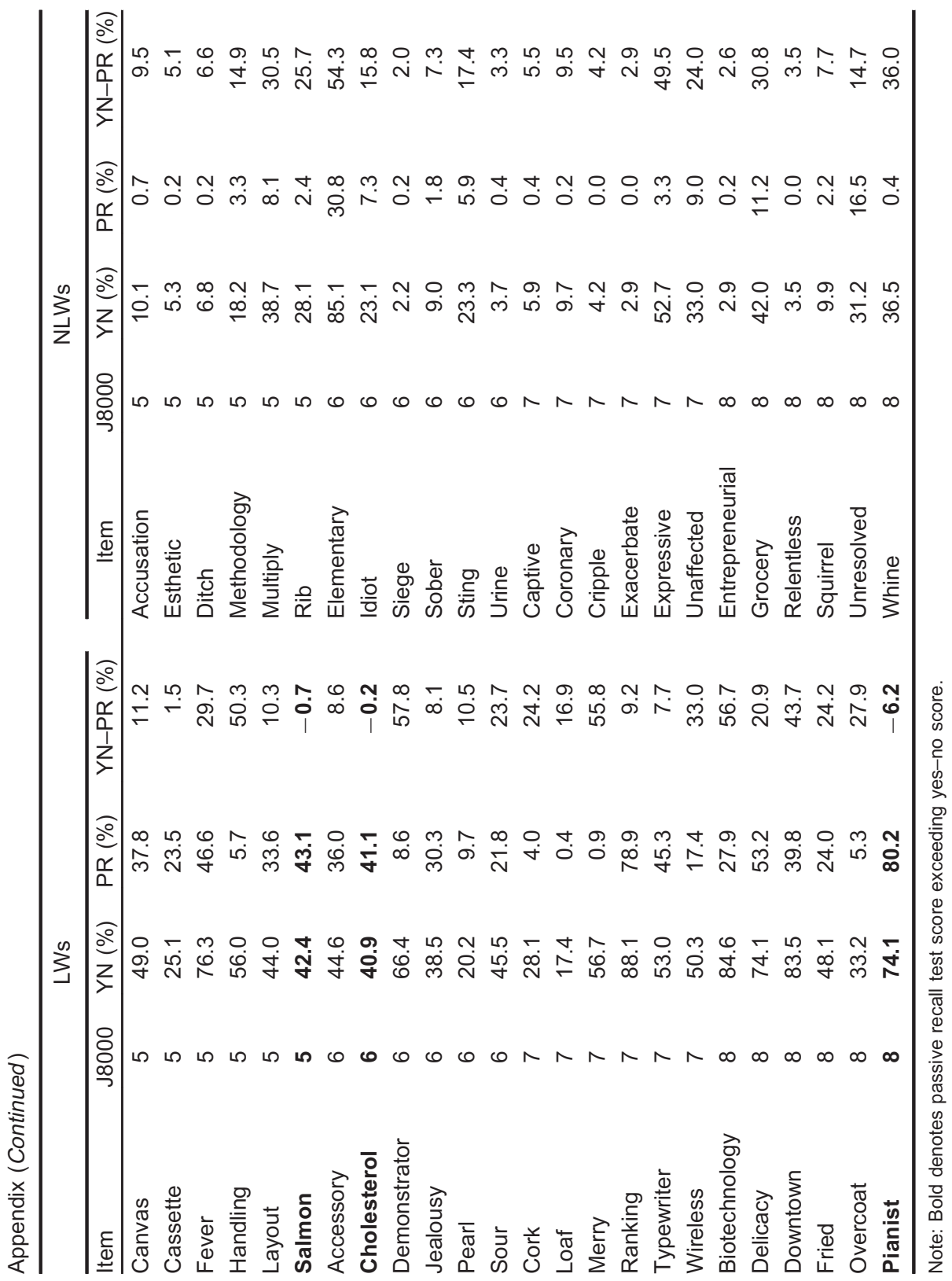

